\title{
Phenytoin Induced Oral Lichenoid Eruption and Melasma: A Case Report
}

\author{
Margret Roji', Midhula Sebastian ${ }^{1}$, Jisha M Lucca ${ }^{2}$, Ranugha PSS ${ }^{3}$ \\ ${ }^{1}$ Department of Pharmacy Practice, JSS College of Pharmacy, JSS University, Karnataka, INDIA. \\ ${ }^{2}$ Department of Pharmacy Practice, College of Clinical Pharmacy, Imam Abdulrahman Bin Faisal University, Dammam, KSA \\ ${ }^{3}$ Department of Dermatology, Venereology and Leprosy, JSS Medical College and Hospital, Mysore, INDIA.
}

\section{ABSTRACT}

In India, phenytoin is the most frequently prescribed medication for most forms of epilepsy except for absence seizures. It has been associated with various cutaneous reaction, however Oral Lichenoid Drug Reaction (OLDR) are rarely documented. We report a case of Phenytoin induced Oral Lichenoid Eruption and Melasma.

Key words: Phenytoin, Melasma, Oral lichenoid eruption.

\section{INTRODUCTION}

Drug-induced pigmentation represents 10 to $20 \%$ of all cases of acquired hyper pigmentation and usually occurs on photo exposed part of the skin. Drugs acting on the central nervous system have been frequently reported to cause Oral lichenoid drug eruption. The reaction can occur months or even years after taking the medication. Phenytoin is a widely prescribed first line antiepileptic agent because of its high efficacy, low cost and availability. ${ }^{1}$ The adverse effects of phenytoin involve dermatologic, gastrointestinal, neurologic, psychiatric, hematologic and hepatic systems. Even though dermatological reactions are frequent with phenytoin, Oral Lichenoid Drug Reaction (OLDR) are not often documented. ${ }^{2}$ Reporting here is an interesting case of OLDR with melasma secondary to phenytoin use in an epileptic patient.

\section{CASE REPORT}

A 25-year old unmarried man from rural background with primary education, visited dermatology department of a university hospital. On presentation, the complaints of hyper pigmented macular patches over cheeks and jaws in the past 11 months and subsequently it spread to his lower lip. On examination, hyper pigmented plaques with mild scaling were present over the lower lip with melasma over the maxillary area (Figure 1). Oral and genital mucosa, cutaneous examination was normal. Routine blood investigations did not reveal any abnormality. He is a known case of seizure disorder on phenytoin in the past 4 years (200 mg daily for the first 2 years and 300 mg daily for 2 years). Skin biopsy could not be performed as the patient was not willing. With the history and clinical findings, a diagnosis of phenytoin induced melasma with lichenoid eruption involving the lips was made. The patient was started on topical steroids and topical depigmenting agents for lip and melasma lesions respectively. The anticonvulsant was changed to valproate with neurologist consultation. The patient is on regular follow-up with improvement in the skin lesions.

\section{DISCUSSION}

Lichenoid drug reaction is common that affect skin and mucosa. Even though cutaneous involvement is common, isolated oral lesions have also been described. ${ }^{3}$ OLDR
DOI: 10.5530/ijopp.11.1.10

Address for correspondence: Jisha M Lucca, MPharm, Ph.D, Lecturer, Asst. Professor College of Clinical Pharmacy, Imam Abdulrahman Bin Faisal University, Dammam, KSA. Phone no: +9660558181537 Email Id: Jjmlucca@iau.edu.sa

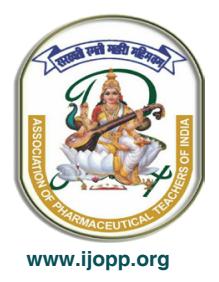




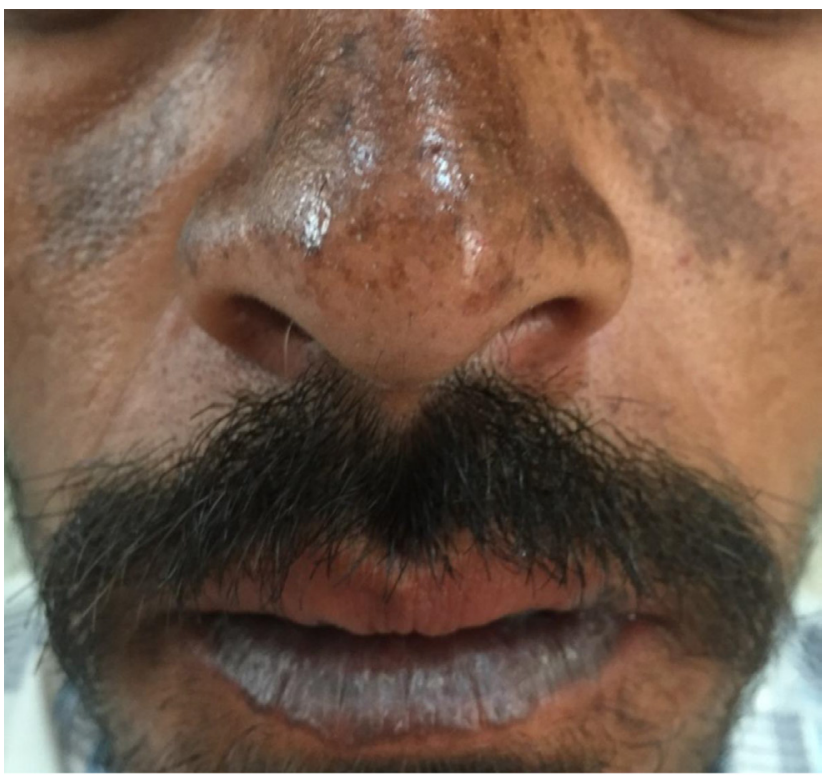

Figure 1: Well defined Hyper pigmented macules over and around the nose; OLDR lesions on Upper and lower lips.

may be considered as a disease itself or an exacerbation of existing oral lichen planus (OLP) by presence of medication (lichenoid drug reaction) or dental material (contact hypersensitivity). The causes for oral lichenoid reaction (OLR) are identifiable, where as it is idiopathic for OLP. ${ }^{4}$ Antiepileptic drugs induced OLDR are limited to carbamazepine and the reports of phenytoin induced OLDR are hardly exist. The intraoral sites of predilection of OLD include the posterior buccal mucosa, tongue, floor of mouth, palate, and alveolar ridges. ${ }^{3}$ There appears to be a preference for unilateral distribution. But our patient had isolated lip involvement which is rare. ${ }^{5}$

Drugs like NSAIDs, anti-hypertensives (beta blockers and ACEIs,) anti-malarials and anti-retrovirals frequently reported to cause OLR. ${ }^{6}$ The common cutaneous reactions of Phenytoin include maculopapular rash, SJS/TEN, erythroderma, vasculitis, fixed drug eruption, DRESS and pseudolymphoma. ${ }^{7}$ Reactions like melasma, lupus, IgA bullous dermatosis and purple hand syndrome are rarely reported with phenytoin. Patients on longterm phenytoin can manifest with gingival hypertrophy, coarsening facies and hirsuitism. ${ }^{3}$ Lichenoid eruption, particularly oral has rarely been reported in the literature.

Melasma that presents as symmetric hyperpigmented macules and patches on the face. Phenytoin has 5-10\% of incidence of causing melasma with usual onset of minimum six months. Hence in our case phenytoin is the underline cause for melasma. Onset of OLDR is highly variable, from 6months to 3 years depends on the drug. ${ }^{8}$ Therefore, it is difficult to establish a clear temporal relationship between initiation of medication and onset of OLDR. In our case the first symptom of
OLDR appeared after 2 years of initiation of phenytoin therapy which persisted and worsened in the following months. We observed the appearance of both reactions after increasing the dose of phenytoin in our patient.

According to the causative medication the pathogenesis of drug-induced pigmentation varies. The pathogenesis of OLDR is believed as cell-mediated immunological disease, but the triggering factors for the immune response are unidentified. But many researchers were found that langerhans cells plays a major in the pathogenesis of OLDR. ${ }^{6}$ The proposed mechanism in phenytoin induced melasma is post-inflammatory hyperpigmentation which often worsened by sun exposure. ${ }^{9}$ In our patient, his occupation(farmer) might explain the increased pigmentation.

Foremost step in the management of OLDR and melasma is the identification and elimination of causative drugs. Evaluation of risk benefit ratio of suspected drug is required before the withdrawal of the suspected drug. If withdrawal of the suspected drug is not possible or alternative drug therapy is not available, then steroid can be considered for the management of both OLDR and melisma. ${ }^{9}$

Even though melasma is not a complicated skin reaction untreated OLDR can end up in malignancy. ${ }^{10}$ Epilepsy is a life-threatening condition which requires lifelong therapy, so we decided to switch phenytoin to valproic acid. Valproic acid and topiramate are nonaromatic antiepileptic drugs which can be considered as safer alternatives for aromatic antiepileptic drugs like phenytoin, carbamazepine, phenobarbital and lamotrigine in the management of OLDR. ${ }^{6}$ Even after the discontinuation of the suspected drug, it takes several months for the complete resolution of symptoms. We are waiting the patient for further follow ups.

\section{CONCLUSION}

Oral lichenoid drug eruption is hardly ever reported with phenytoin therapy Melasma and Oral lichenoid drug eruption may occur after increasing the dose of Phenytoin. So, all health care professionals should be more vigilant on patients taking Phenytoin.

\section{ACKNOWLEDGEMENT}

The authors sincerely thank to JSS Hospital for all the support.

Indian Journal of Pharmacy Practice, Vol 11, Issue 1, Jan-Mar, 2018 
ABBREVIATIONS USED

OLP: Oral Lichen Planus; OLR: Oral Lichenoid Reaction; SJS: Stevens Johnson Syndrome; TEN: Toxic Epidermal Necrosis; NSAIDS: Nonsteroidal Anti Inflammatory Drugs; ACE-I: Angiotensin converting enzyme inhibitors.

\section{SUMMARY}

Drugs acting on the central nervous system have been frequently reported to cause Oral lichenoid drug eruption The reaction can occur months or even a year after taking the medication. Oral lichenoid drug eruption are hardly ever reported with phenytoin therapy Melasma and Oral lichenoid drug eruption may occur after increasing the dose of Phenytoin

\section{REFERENCES}

1. Patil N, Kunder SK, Avinash A, et al. Phenytoin-induced acute generalized exanthematouspustulosis.Asian J Pharm Clin Res. 2016;9(2):510-11.

2. Misra UK, Kalita J, Rathore C. Phenytoin and carbamazepine cross reactivity: report of a case and review of literature. Postgrad Med J. 2003;79(938):703-4.

3. Victoria W, Julia B, Lyubov B, David. Oral Lichenoid Drug Eruption: A Report of a Pediatric Case and Review of the Literature Pediatric Dermatology. 2009;26(4):458-64.

4. Sareen C, Pathak A, Ahuja P, Kohli M. A diagnostic dilemma: oral lichen planus or lichenoid reaction - a series of case reports. J. Advanced Medical and Dental Sciences Research. 2015;3(3):98-100.

5. Rotim Z, Bolanca Z, Rogulij AA, et al. Oral lichen planus and oral lichenoid reaction- an update. ActaClin Croat. 2015;54(4):516-8.

6. Barisi E, Senoovenl B, Tuzuner T, Gultekin SE. Oral lichenoid lesions related to drugs: review of clinicopathological features and differential diagnosis. European Journal of Inflammation. 2014:12(2):217-25.

7. Corbett HA, Dana JW, Gonzales PJ, et al. Wolters Kluwer Clinical Drug Data. Drug information hand Book. editors. $25^{\text {th }}$ ed. USA: Lexicomp. 2016;1444-9.

8. Sarkar R, Arora P Melasma update. Indian Dermatology online journal [serial online] 2014 Oct-Dec [cited 2017 Jun]; 5(4):425-7. Available from: http://www.idoj.in

9. Bangherani N, Gianfldoni S, Smoller B. An over view of melasma. Journal of pigmentary disorders. 2015;2(10):1-18.

10. Rotim Z, et al. Oral lichen planus and lichenoid reaction. Acta Clin Croat. 2015 54(4):516-20. 